\title{
Effect of Interlayers on Microstructure and Properties of 2205/Q235B Duplex Stainless Steel Clad Plate
}

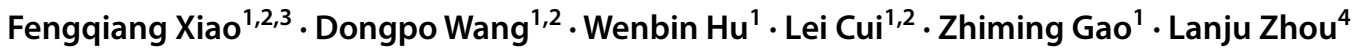

Received: 27 August 2019 / Revised: 9 October 2019 / Published online: 18 December 2019

(c) The Chinese Society for Metals (CSM) and Springer-Verlag GmbH Germany, part of Springer Nature 2019

\begin{abstract}
In this research, 2205/Q235B clad plates were prepared by a vacuum hot rolling composite process. The effects of adding Fe, $\mathrm{Ni}$, and $\mathrm{Nb}$ interlayers on the bonding interface structures and the shear strengths of the clad steel plates were studied. The results showed that 2205 duplex stainless steel and the three interlayers produced a large amount of plastic deformation and low-angle boundaries, and the main structures were the recrystallized and deformed grains. There were many recrystallized grains in the microstructure of the Q235B low-carbon steel due to the low deformation in the rolling process. The Fe interlayer had better wettability with the two kinds of steel, but the lower strength led to the reduction of shear strength by about $14 \mathrm{MPa}$ compared with the original clad steel plate. The C element in the Q235B low-carbon steel easily diffused into the Fe interlayer, and the clad steel plate attained a poor corrosion resistance because a large decarburization area was formed. The $\mathrm{Nb}$ interlayer reacted with the Mo element in the 2205 duplex stainless steel to form an Nb-Mo binary alloy, which generated long-banded ferrite. The decarburization area was also produced because the $\mathrm{Nb}$ reacted with the $\mathrm{C}$ element in the Q235B to form hard and brittle $\mathrm{NbC} x$. As a result, the shear strength was significantly reduced by about $282 \mathrm{MPa}$, and the corrosion resistance of the bonding surface was deteriorated. The Ni interlayer did not react with the alloy elements in both sides, and therefore effectively prevented element diffusion and improved the corrosion resistance of the bonding surface. Due to the low strength of the Ni interlayer and the increased number of bonding surfaces of the clad steel plates, the shear strength was reduced to some extent (about $40 \mathrm{MPa}$ ), but it still met the engineering application standards.
\end{abstract}

Keywords 2205/Q235B clad steel plate $\cdot$ Fe interlayer $\cdot \mathrm{Ni}$ interlayer $\cdot \mathrm{Nb}$ interlayer $\cdot$ Decarburization area $\cdot$ Shear strength

\section{Introduction}

The differences in the compositions of the base material and the covering material in clad steel plate lead to strong element diffusion near the bonding interface during the preparation process. A brittle phase, oxide, and defects that hinder

Available online at http://link.springer.com/journal/40195.

Lei Cui

leicui@tju.edu.cn

1 School of Materials Science and Engineering, Tianjin University, Tianjin 300350, China

2 Tianjin Key Laboratory of Advanced Joining Technology, Tianjin University, Tianjin 300350, China

3 Shandong High-tech Investment Corporation, Jinan 250101, China

4 Shandong Iron \& Steel Group Co., LTD, Jinan 250101, China bonding easily occur at the bonding interfaces of composite plates, which seriously affects the performance of the bonding interface and even affects the performances of the component materials [1-4].

By adding an interlayer with certain plasticity, strength, and wettability in the middle of composite plates, the diffusion of elements and the formation of a brittle phase and oxide in the interface can be effectively prevented [5]. In addition, interlayer material can also improve the bonding quality of composite plate. However, if an inappropriate interlayer is selected, brittle intermetallic compounds will be formed between the interlayer and the matrix, and their composite properties will be reduced [6]. Therefore, the interlayer material and thickness should be determined according to the type of composite metal materials, the application field, and the technical requirements of the actual production process. Hence, the interfacial bonding rate and bonding strength of clad steel plate can be effectively improved. 
Investigations have found that by adding an interlayer with certain plasticity, strength, and wettability in the middle of stainless steel composite plate, such as Ag-based materials, Al-based alloys [7], and pure Ni material [8-10], the diffusion of elements $[8,9]$ and the formation of interfacial oxides [10] can be effectively prevented, and the bonding quality of composite plate can be improved [7]. In the process of the hot rolling preparation of titanium/steel composite plate, copper, nickel, niobium, and other elements are often used as interlayer materials to improve the mechanical properties of the composite plate [11-13].

$\mathrm{Li}$ et al. [14] found that Ni interlayers with different thicknesses $(0,0.1$, and $0.2 \mathrm{~mm})$ could significantly prevent the diffusion of elements at the junction of hot-rolled 316-Q345 composite plate, and the proportion of interfacial oxides was reduced. However, the bonding strength of the interface was reduced to some extent, and the thickness of the $\mathrm{Ni}$ interlayer must be controlled.

Luo et al. [15] studied the effect of an $\mathrm{Nb}$ interlayer on the structure and properties of TA2-304L composite plate. The results demonstrated that the $\mathrm{Nb}$ interlayer could effectively prevent the formation of many intermetallic compounds, such as $\mathrm{Fe}_{2} \mathrm{Ti}, \mathrm{Cr}_{2} \mathrm{Ti}$, and $\mathrm{NiTi}_{2}$, at the interface of the composite plate. In addition, FeNb intermetallic compounds were formed between the $\mathrm{Nb}$ interlayer and stainless steel, and the interfacial shear strength was significantly improved to $338 \mathrm{MPa}$, exhibiting excellent performance. Xie et al. [16] also obtained similar results in their research. Yu et al. $[17,18]$ studied the influence of different rolling temperatures [17] and reduction rates [18] on the bonding strength of titanium-carbon steel composite plate with a pure iron interlayer. The results indicated that when the rolling temperature was $850{ }^{\circ} \mathrm{C}$, the titanium/steel plate with a pure iron interlayer had the best composite effect. The pure iron interlayer was beneficial for improving the composite strength of titanium/steel composite plate with a small reduction rate. Both the composite plates with and without the pure iron interlayer could reach a higher composite strength when the reduction rate was large. Liu et al. [19] analyzed the effects of surface reparation condition, atmosphere condition, vacuum degree, rolling temperature, rolling reduction ratio, interlayer, heat treatment on the microstructure, interface characteristics, and mechanical properties of stainless steel clad plate. They found that the bonding mechanism of hot-rolled stainless steel clad based on the oxide film theory, diffusion theory, recrystallization theory, and three stage theory. Liu et al. [20] also found that he interface with a thickness of 300-400 nm contains refined grains accompanying with many $\mathrm{Cr}_{23} \mathrm{C}_{6}$ and $\mathrm{MnSi}_{2} \mathrm{O}_{4}, \mathrm{SiO}_{2}$ particles.
The majority of scholars have used stainless steel-carbon steel, stainless steel-titanium alloy, and titanium alloy-carbon steel as the research objects, and the influences of the interlayers on the element diffusion and bonding strength have been investigated from the aspects of interlayer material selection, interlayer thickness, rolling technology, and others. Many meaningful research results have been obtained. The interlayer is added to prevent the mutual diffusion of elements at the junction; the mutual diffusion of elements not only affects the bonding strength of composite plate, but also plays an important role in the surface properties of materials. However, there are relatively few studies on this aspect. In addition, the stainless steel used in stainless steel composite plate is usually austenitic stainless steel, such as 304 or 316 , whereas there is very little research on 2205 duplex stainless steel composite plate with an interlayer.

Consequently, this study used 2205 duplex stainless steel and Q235B low-carbon steel as research objects and studied the effects of the addition different types of interlayers between the two kinds of steel plates. The effects of different interlayer materials on the element diffusion, shear strength, and corrosion resistance were investigated. The interaction of different interlayers with 2205 duplex stainless steel and Q235B low-carbon steel was studied at the microscopic level.

\section{Experimental}

\subsection{Materials and Fabrication Process}

The two base materials for cladding were 2205 duplex stainless steel and Q235B low-carbon steel. Their chemical compositions are listed in Tables 1 and 2, respectively. The interlayer materials selected in this study were pure $\mathrm{Fe}, \mathrm{Ni}$, and $\mathrm{Nb}$ foils. The thicknesses of the three materials were all $100 \mu \mathrm{m}$, and their specific chemical compositions are listed in Table 3. A group of composite plates without any intermediate layer was selected to compare the structures and performances.

The hammerhead of a Gleeble 3800 hot simulation experiment machine was used to clamp the duplex stainless steel $(\varnothing 10 \mathrm{~mm} \times 7 \mathrm{~mm})$ and low-carbon steel $(\varnothing 10 \mathrm{~mm} \times 9 \mathrm{~mm})$

Table 2 Chemical composition of Q235B low-carbon steel (wt\%)

\begin{tabular}{llllll}
\hline $\mathrm{C}$ & $\mathrm{Si}$ & $\mathrm{Mn}$ & $\mathrm{S}$ & $\mathrm{P}$ & $\mathrm{Fe}$ \\
\hline 0.177 & 0.147 & 0.348 & 0.014 & 0.014 & Bal. \\
\hline
\end{tabular}

Table 1 Chemical composition of 2205 stainless steel (wt\%)

\begin{tabular}{llllllllll}
\hline $\mathrm{C}$ & $\mathrm{Si}$ & $\mathrm{Mn}$ & $\mathrm{Cr}$ & $\mathrm{Ni}$ & $\mathrm{Mo}$ & $\mathrm{S}$ & $\mathrm{P}$ & $\mathrm{N}$ & $\mathrm{Fe}$ \\
\hline 0.038 & 0.67 & 1.49 & 22.31 & 6.31 & 3.04 & 0.005 & 0.037 & 0.18 & Bal. \\
\hline
\end{tabular}


Table 3 Chemical compositions of three interlayers (wt $\%$ )

\begin{tabular}{lclll}
\hline Group & $\mathrm{Fe}$ & $\mathrm{Ni}$ & $\mathrm{Nb}$ & $\begin{array}{l}\text { Oth- } \\
\text { ers }\end{array}$ \\
\hline Fe interlayer & 99.69 & - & - & Bal. \\
Ni interlayer & 0.023 & 99.89 & - & Bal. \\
Nb interlayer & 0.038 & - & 99.204 & Bal. \\
\hline
\end{tabular}

cylinders. After that, compression simulation experiments were conducted. During the rolling process, the heating temperature was $1200{ }^{\circ} \mathrm{C}$, the heating speed was $5^{\circ} \mathrm{C} / \mathrm{s}$, and the heat preservation time was $3 \mathrm{~min}$. One, two, three, and four passes were rolled after the end of heat preservation, and the plates were finally air cooled to room temperature. The specific rolling process is shown in Table 4.

\subsection{Microstructure Characterization}

Metallographic samples were cut from the 2205/Q235B clad steel plate, ground, and polished as per the standard metallographic procedure. The clad steel plate was corroded by two corrosives. A $40 \% \mathrm{KaOH}$ solution was used for electrolytic corrosion on the side of the 2205 duplex stainless steel with a constant potential voltage of $8 \mathrm{~V}$ for $10 \mathrm{~s}$. The side of the Q235B low-carbon steel was corroded by a $4 \%$ alcohol nitrate solution. The microstructures were observed using an OLYMPUS GX71 metallographic microscope. The distribution and content of the alloying elements were determined via energy disperse spectroscopy (EDS) analysis (Zeiss Sigma 500/VP field emission scanning electron microscope). Electron backscattered diffraction (EBSD) analysis was used to conduct a detailed comparative study on the grain size, phase type and distribution, grain boundary, and other factors at the bonding surfaces of the composite plates.

\subsection{Mechanical Properties}

The shear strengths of the 2205/Q235B duplex stainless steel composite plate samples were tested according to the GBT 6396-2008 standard [21]. The shear strength could not be tested by conventional methods due to the small size of the thermal simulation samples. Therefore, the method as

Table 4 Rolling technological parameters

\begin{tabular}{llllll}
\hline Parameters & \multicolumn{5}{l}{ Pass number } \\
\cline { 2 - 6 } & 0 & 1 & 2 & 3 & 4 \\
\hline Pass reduction ratio $(\%)$ & - & 20 & 20 & 20 & 20 \\
Temperature $\left({ }^{\circ} \mathrm{C}\right)$ & 1200 & 1080 & 1030 & 980 & 930 \\
Thickness $(\mathrm{mm})$ & 16.7 & 13.4 & 10.7 & 8.6 & 6.9 \\
Deformation $(\mathrm{mm})$ & - & 3.3 & 2.7 & 2.1 & 1.7 \\
\hline
\end{tabular}

shown in Fig. 1 was adopted. Shear samples with sizes of $10 \mathrm{~mm} \times 5 \mathrm{~mm} \times 5 \mathrm{~mm}$ were cut from thermal simulation samples via wire cutting. The side of the 2205 stainless steel was fixed in the groove of the combined fixture, and the side of the Q235B low-carbon steel was exposed to the outside of the fixture. The fastening bolts at the top of the fixture were then rotated to clamp the shear samples, and the shear tests were conducted on an MTS-E45 microcomputer-controlled electronic universal test machine. Scanning electron microscopy/energy disperse spectroscopy (SEM/EDS) was used to observe the shear fracture and analyze the alloy elements. The micro-hardness of the composite plate was measured by an HV-1000A micro-hardness tester. The load was $25 \mathrm{~g}$, and the loading time was $10 \mathrm{~s}$. Testing was performed from the interface to the left and right, and hardness was measured every 20 microns.

\subsection{Corrosion Properties}

To compare the corrosion resistance at the joints of 2205/ Q235B clad steel plates with different kinds of interlayers, acid immersion tests were conducted. The cold inserts were used to seal the 5 surfaces of the samples, exposing only the cross sections. The prepared samples were immersed in a $5 \mathrm{~mol} / \mathrm{L} \mathrm{HCl}$ solution for $24 \mathrm{~h}$ after corresponding grinding and polishing processes. The corrosion morphologies were observed via SEM.

\section{Results and Discussion}

\subsection{Microstructures}

Figure 2 presents the influence of different interlayers on the cross-sectional microstructures of the 2205/Q235B

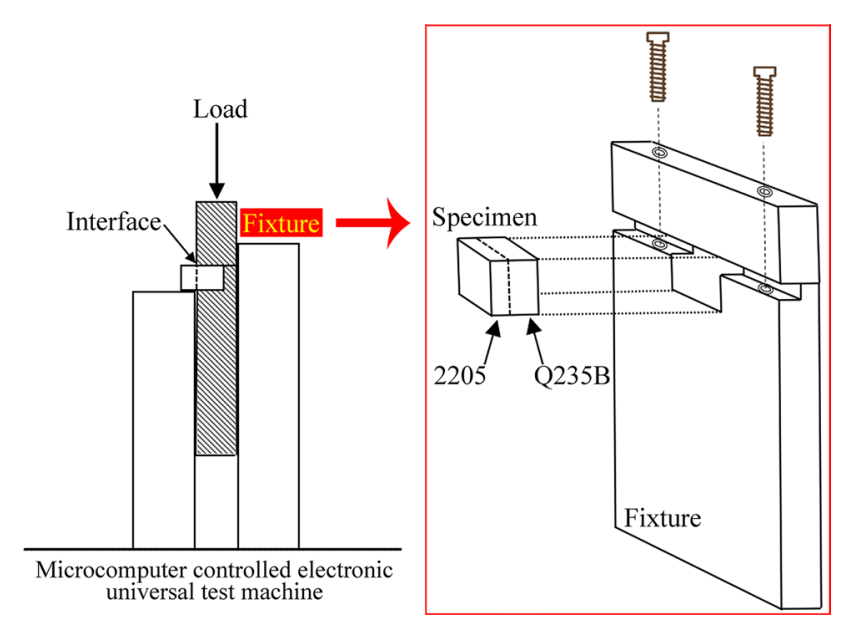

Fig. 1 Schematic diagram of shear test sample 
composite plate. Four groups of composite plates were well combined and presented no obvious defects. The microstructure of the 2205 stainless steel side in the original 2205/ Q235B clad steel plate was primarily fine-strip austenite and ferrite. The microstructure of the side of the Q235B low-carbon steel was ferrite and pearlite, but the side near the bonding surface was mainly ferrite, forming a typical carbon-poor zone with a width of about $44.9 \mu \mathrm{m}$ (as shown in Table 5). After adding $\mathrm{Fe}, \mathrm{Ni}$, and $\mathrm{Nb}$ interlayers, the microstructures of the 2205 stainless steel and Q2345B low-carbon steel far from the junction were also fine-strip austenite and ferrite, and ferrite and pearlite, respectively. However, the microstructures of the composite plates with the three intermediate layers at the bonding surface were quite different.

No obvious interlayer could be seen at the bonding surface when the Fe interlayer was used. The Fe element is
Fig. 3 EDS results of the cross sections of the 2205/Q235B clad steel plates with different interlayers: a without interlayer; $\mathbf{b} \mathrm{Fe}$ interlayer; c Ni interlayer; $\mathbf{d} \mathrm{Nb}$ interlayer

the main element in both 2205 stainless steel and Q235B low-carbon steel, and the interlayer had excellent wettability with both kinds of steel. During the hot rolling process, the pure Fe interlayer was completely fused with the two steels. The thickness of the decarburization area on the side of the low-carbon steel was about 41.5 microns (as shown in Table 5) and was lower than that of the original composite plate. This indicates that the $\mathrm{Fe}$ interlayer played a certain role in impeding the diffusion of elements. After the addition of the $\mathrm{Ni}$ and $\mathrm{Nb}$ interlayers, obvious intermediate layers could be seen at the positions of the bonding surface. However, the addition of the $\mathrm{Ni}$ interlayer basically led to the disappearance of the decarburization area, while the
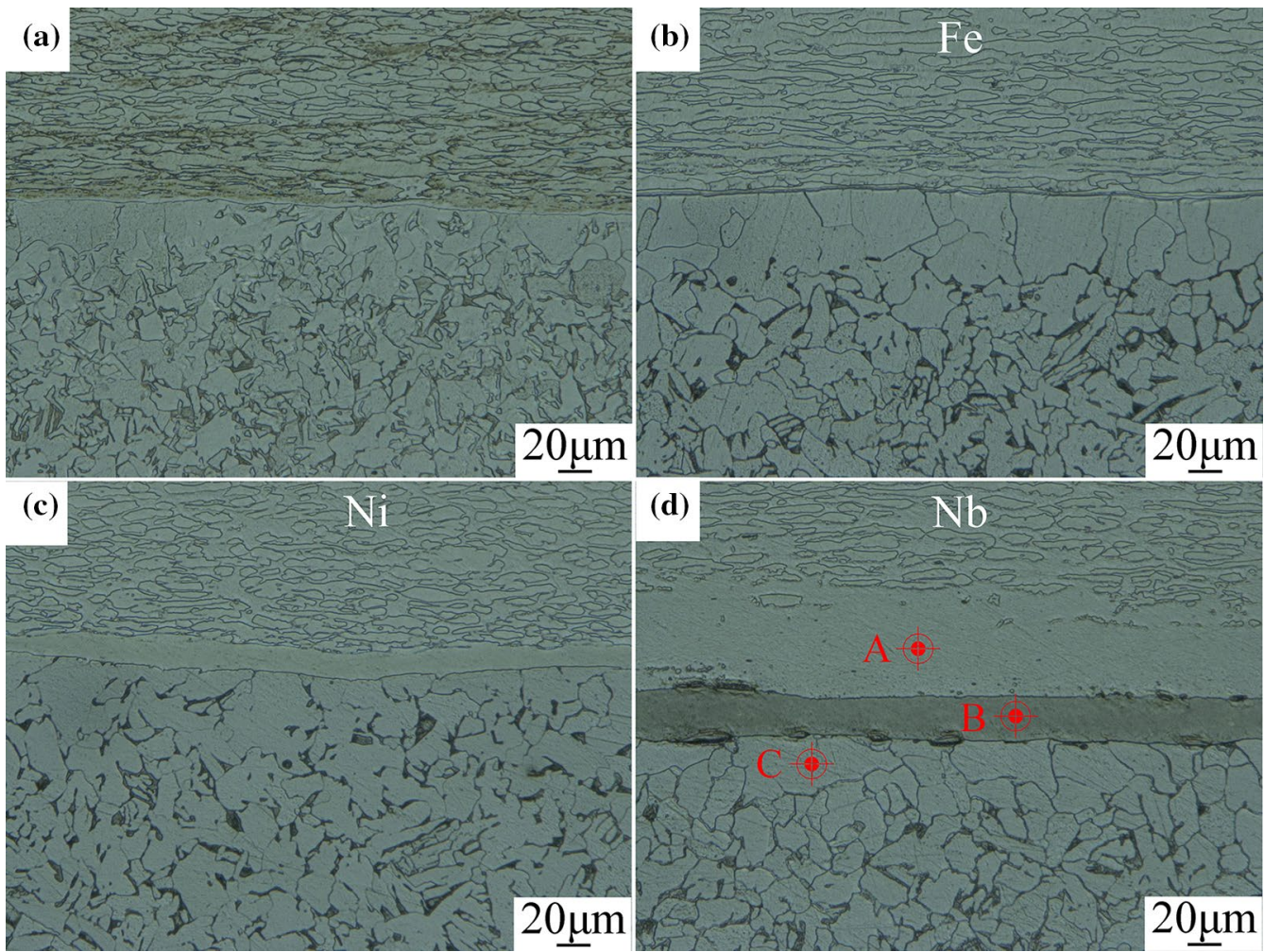

Fig. 2 Microstructures of the cross sections in the 2205/Q235B clad steel plates with different interlayers: a without interlayer; b Fe interlayer; c $\mathrm{Ni}$ interlayer; $\mathbf{d} \mathrm{Nb}$ interlayer

Table 5 Thickness of the decarburization area on the side of the Q235B low-carbon steel near the bonding zone $(\mu \mathrm{m})$

\begin{tabular}{llllllll}
\hline Group & 1 & 2 & 3 & 4 & 5 & 6 & Average \\
\hline Without interlayer & 45 & 44.6 & 45.3 & 44.7 & 43.9 & 45.6 & 44.9 \\
Fe interlayer & 42.1 & 41.4 & 41.2 & 42.3 & 41.3 & 40.9 & 41.5 \\
Ni interlayer & - & - & - & - & - & - & - \\
Nb interlayer & 34.5 & 34.2 & 34.1 & 35.3 & 35.6 & 33.8 & 34.6 \\
\hline
\end{tabular}




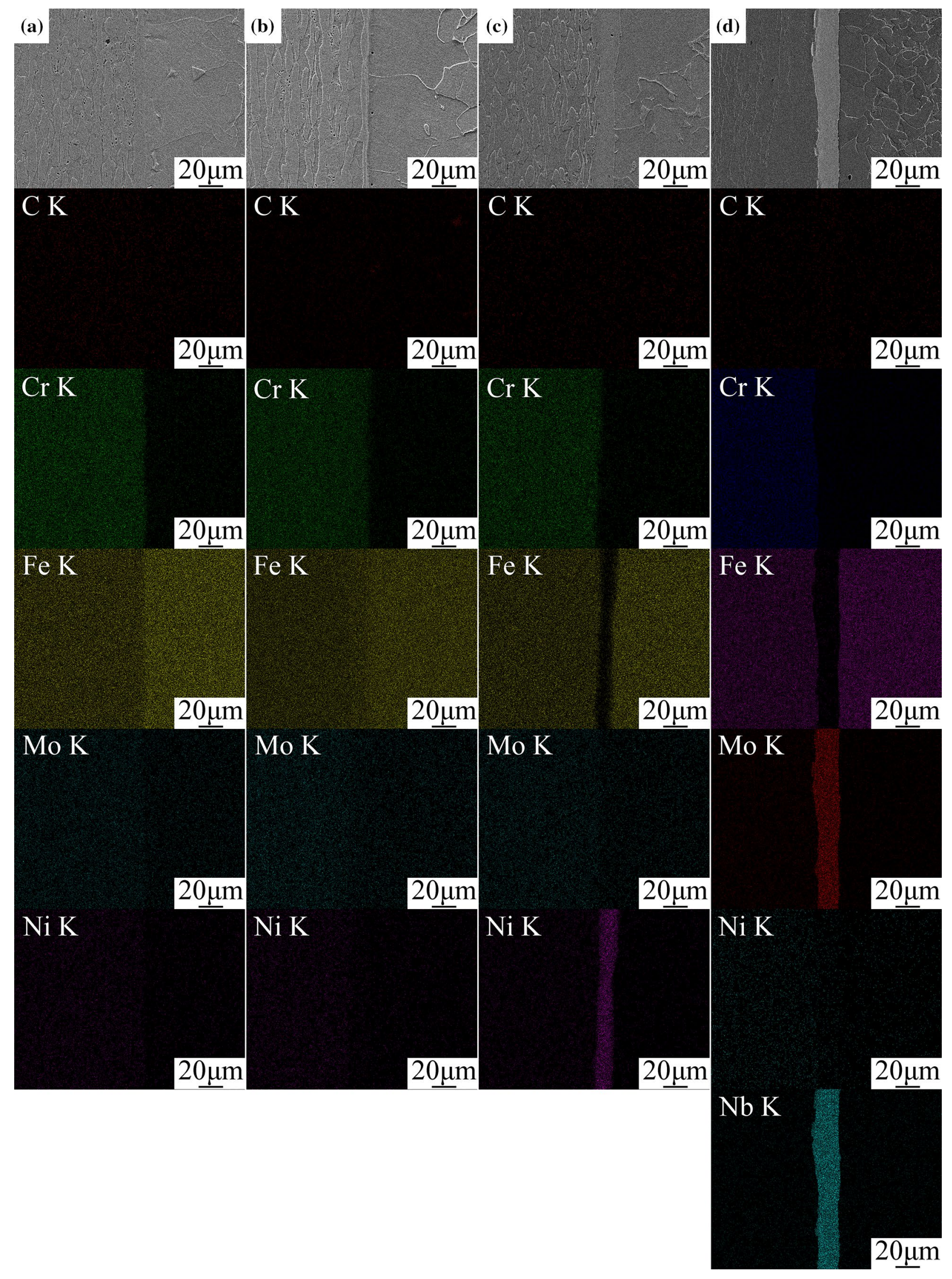



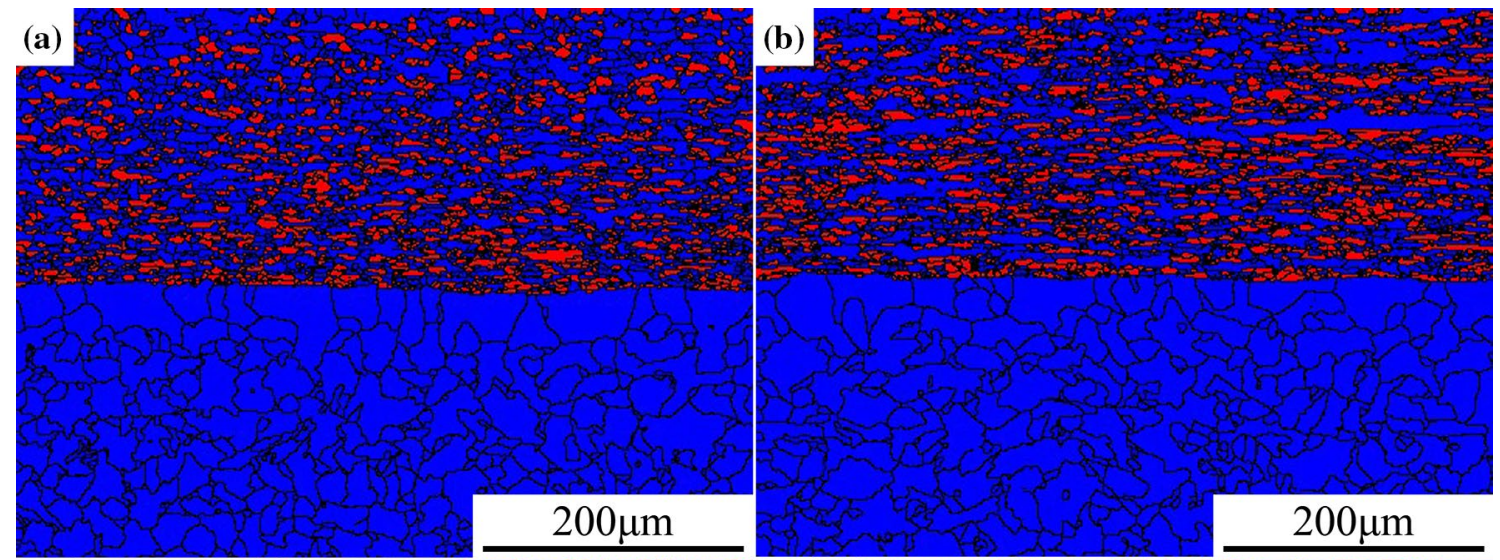

(c)

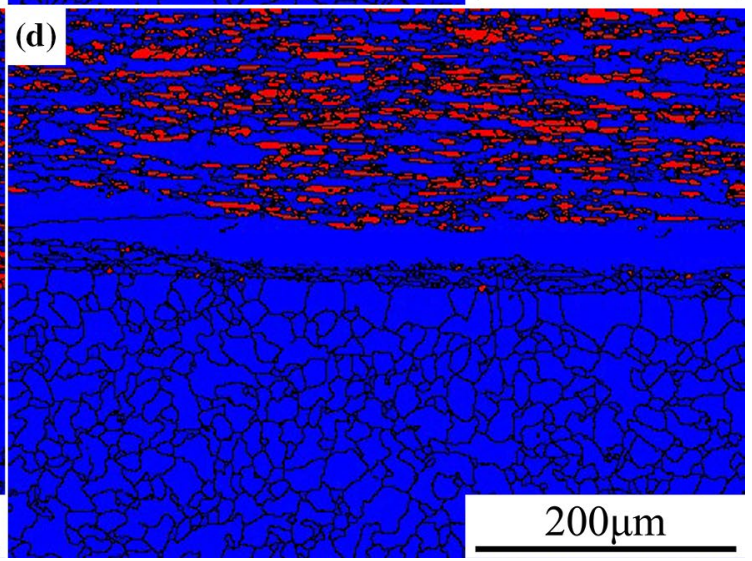

Fig. 4 Phase transition laws of the cross sections of the 2205/Q235B clad steel plates with different interlayers: a without interlayer; $\mathbf{b}$ Fe interlayer; $\mathbf{c} \mathrm{Ni}$ interlayer; $\mathbf{d} \mathrm{Nb}$ interlayer

$\mathrm{Nb}$ interlayer only made the decarburization area greatly decrease, as shown in Table 5. These results illustrate that the $\mathrm{C}$ element in the low-carbon steel diffused to the $\mathrm{Nb}$ interlayer, generating a decarburization area dominated by ferrite near the bonding surface on the side of the low-carbon steel. Additionally, the addition of the $\mathrm{Nb}$ interlayer made the side of the 2205 stainless steel near the interlayer form a large microstructure, while the addition of the $\mathrm{Ni}$ interlayer did not produce this phenomenon. Therefore, in terms of the diffusion effect of obstructing elements, the Ni interlayer is the best, the $\mathrm{Nb}$ interlayer is the second best, and the Fe interlayer is the worst. However, the special structure formed by the addition of the $\mathrm{Nb}$ interlayer in the 2205 stainless steel and Q235B low-carbon steel needs to be further studied.

Figure 3 shows the EDS detection results of the cross sections of the four groups of 2205/Q235B clad steel plates. There are some similar distribution rules of alloying elements; the contents of the $\mathrm{Cr}$, Mo, and Ni elements in the 2205 stainless steel were more abundant than those of the Q235B low-carbon steel. Therefore, the EDS test results demonstrate that the distribution densities of these three elements on the side of the 2205 stainless steel were higher.
However, the Q235B low-carbon steel had a higher content of $\mathrm{Fe}$ element, which resulted in a higher distribution density. Because it is a lightweight element, there existed a large error in the $\mathrm{C}$ element detection results using the EDS detection method. Therefore, the distribution of the $\mathrm{C}$ element in the 2205 stainless steel and Q235B low-carbon steel had no obvious boundary. After the addition of the Fe interlayer, no obvious boundary between the interlayer and the two kinds of steel could be seen in the EDS detection results because the main elements in these two kinds of steel are $\mathrm{Fe}$ elements. It can be seen that the distribution density of $\mathrm{Ni}$ elements in the $\mathrm{Ni}$ interlayer exhibited a significant increasing trend, and that the contents of the other elements in the interlayer basically tended toward zero. This indicates that the Ni interlayer could effectively prevent the mutual diffusion of alloy elements. Not only did the $\mathrm{Nb}$ interlayer contain abundant $\mathrm{Nb}$ elements, but the distribution density of the Mo element was very high, whereas the contents of the other elements tended to zero. This result indicates that the $\mathrm{Nb}$ element in the interlayer could react with the Mo element in the 2205 duplex stainless steel to form an Nb-Mo intermetallic compound. As the melting point of pure $\mathrm{Nb}$ is $2468{ }^{\circ} \mathrm{C}$, it is impossible to melt during the hot rolling process. Therefore, 


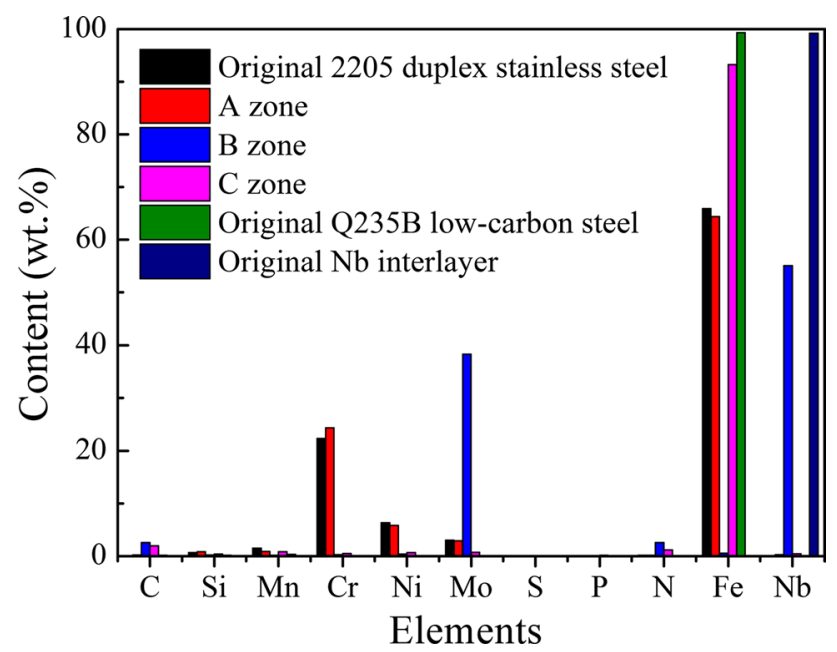

Fig. 5 EDS results of the cross sections of the 2205/Q235B clad steel plates with the $\mathrm{Nb}$ interlayer

the Mo element in the 2205 stainless steel near the bonding surface was diffused into the $\mathrm{Nb}$ interlayer to form an $\mathrm{Nb}-$ Mo binary intermetallic compound [22].

As shown in Fig. 4, EBSD was used to detect the law of phase components at the cross sections of the four groups of clad steel plates, where blue represents BCC and red represents FCC. The Q235B low-carbon steel was totally comprised of the BCC phase, while the 2205 stainless steel contained both FCC (austenite) and BCC (ferritic) phases. The decarburization area in the low-carbon steel near the bonding surface was also the BCC phase. The position of the Fe interlayer contained both FCC and BCC phases and was therefore similar to the interface of clad steel plate without an interlayer. This may be because the Fe interlayer is soft and was blended into the two kinds of steel during the rolling process. When the $\mathrm{Ni}$ interlayer was added, all the interfaces were FCC structures, which is mainly because the $\mathrm{Ni}$ is an FCC structure.

The position of the $\mathrm{Nb}$ interlayer contained not only the BCC phase, but also a small amount of FCC structures. Because the $\mathrm{Nb}$ and the $\mathrm{Nb}-\mathrm{Mo}$ binary intermetallic compound were all BCC structures [22], it is speculated that some other compounds were formed at the position of the $\mathrm{Nb}$ interlayer, though this requires further verification. In addition, a long BCC structure was formed near the interlayer on the side of the 2205 stainless steel. Theoretically, this area was 2205 duplex stainless steel, which should have contained FCC (austenite) and BCC (ferrite) duplex structures, although it only contained BCC (ferrite) structures.

By analyzing the EDS detection results of the side of the 2205 stainless steel near the interlayer (i.e., area A in Fig. 2d), it was found that the content of the Mo element $(2.9 \mathrm{wt} \%)$ was somewhat lower than that of the original 2205 duplex stainless steel (3.04 wt\%), as shown in Fig. 5. The
Mo element is a ferrite-forming element in stainless steel, and the reduction of the content of Mo element should have promoted the transformation of ferrite to austenite, and the formation of austenite with an FCC structure [23]. However, the EBSD test presents a contradictory result. By analyzing Fig. 5, it can be determined that the content of the Cr element (24.33 wt\%) in region A (Fig. 2d), which also promotes the formation of ferrite, was increased compared with that in the original 2205 stainless steel $(22.31 \mathrm{wt} \%)$. The contents of the two kinds of elements that usually promote the formation of ferrite exhibited an opposite trend. The variation tendency of ferrite depends on the contents of two kinds of alloy elements and the strength of ferrite formation. The 2205 duplex stainless steel contained a large amount of $\mathrm{Cr}$ elements (22.31 wt\%) and a small amount of Mo elements (3.04 wt\%), and the Cr element has the higher acceleration for the ferrite [23]. In addition, the increased weight of $\mathrm{Cr}$ elements (2.02 wt\%) was higher than that of Mo elements $(0.14 \mathrm{wt} \%)$. Therefore, considering various factors, although a poor Mo region was formed on the side of the 2205 stainless steel near the interlayer (region A), the increase of the $\mathrm{Cr}$ element content promoted the increase of ferrite content in this region.

Figure 6 presents the influence of the interlayers on the grain sizes and grain boundary angles of the cross sections of the clad steel plates. After the addition of the three interlayers, the content of small-sized grains in the cross section exhibited an increasing trend. The grain size in the cross section was the smallest after the addition of the $\mathrm{Ni}$ interlayer. Although the Fe interlayer is a pure iron material, which is consistent with the main chemical compositions of the two kinds of steel plates, it still hindered the element diffusion during the rolling process. As a result, the grain size was reduced to a certain extent. Although the addition of the $\mathrm{Nb}$ interlayer could effectively hinder the diffusion of alloying elements in the two kinds of steel, the reaction between the $\mathrm{Nb}$ and Mo elements in the 2205 stainless steel generated an $\mathrm{Nb}-\mathrm{Mo}$ binary intermetallic compound. The large-sized ferrite strip structure was formed on the side of the 2205 stainless steel near the interlayer, which enhanced the overall grain size values of the cross section. The variation law of the low-angle boundary in the cross section is basically consistent with that of the small-sized grain. The increased number of low-angle boundaries illustrate that more dislocations existed in the structure, i.e., more serious plastic deformation in this region was generated. This is because the microscopic manifestation of plastic deformation is the movement and accumulation of the dislocation.

Via the detection of grain boundary distribution at the cross sections of the four groups of clad steel plates (Fig. 7), it was found that many sub-grain boundaries were primarily distributed in the 2205 stainless steel. During the rolling process, the deformation of the 2205 stainless steel was 

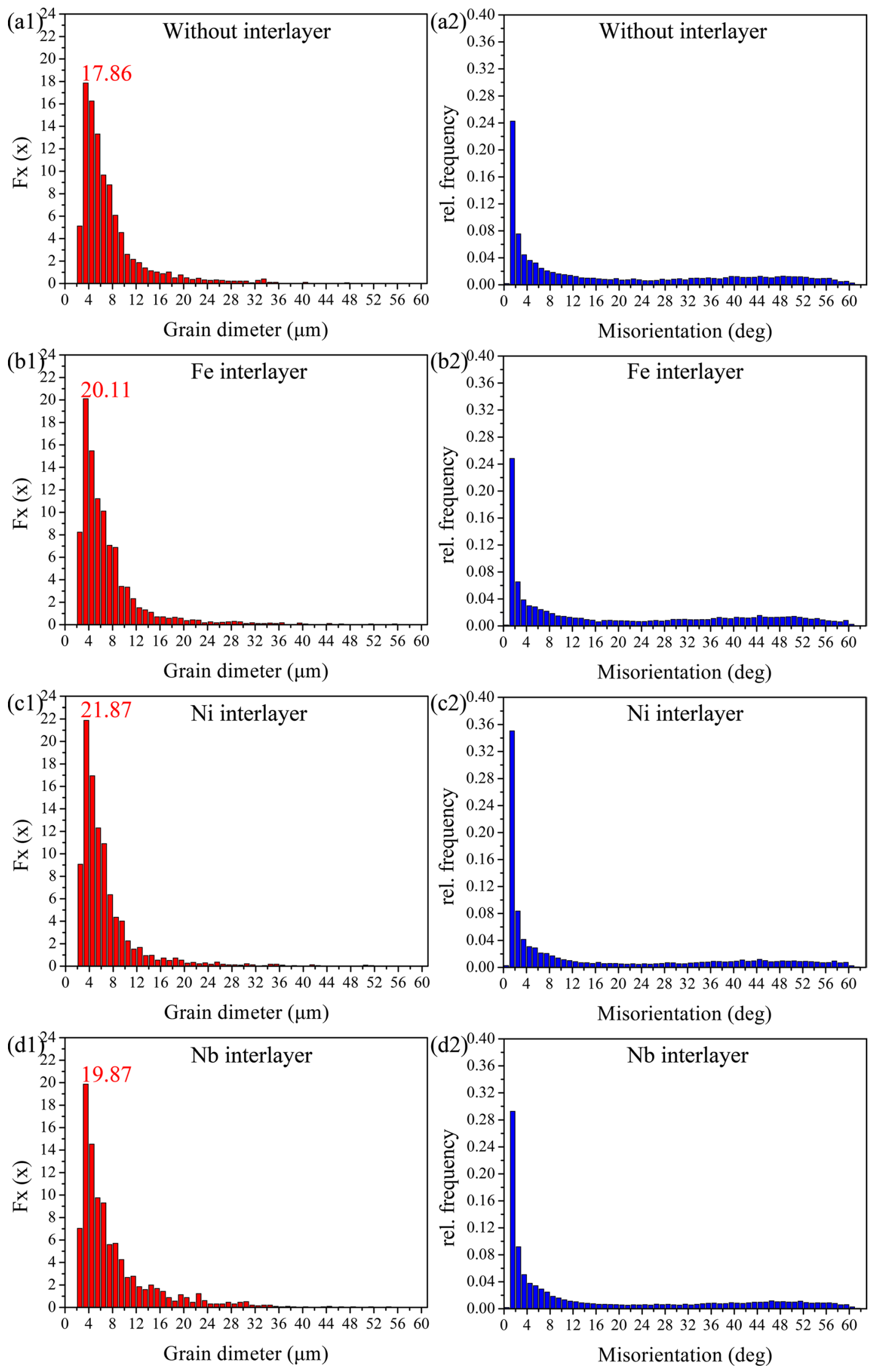
4Fig. 6 Distribution rules of the grain size and grain boundary angle of the cross sections of the 2205/Q235B clad steel plates with different interlayers: $\mathbf{a} 1$ and $\mathbf{a} 2$ without interlayer; $\mathbf{b 1}$ and $\mathbf{b 2} \mathrm{Fe}$ interlayer; c1 and c2 $\mathrm{Ni}$ interlayer; $\mathbf{d 1}$ and $\mathbf{d} \mathbf{2} \mathrm{Nb}$ interlayer

significantly higher than that of the Q235B low-carbon steel. Therefore, more dislocations (i.e., small-angle grain boundaries) were generated in the 2205 stainless steel. In addition, there were a large number of low-angle boundaries in the $\mathrm{Fe}, \mathrm{Ni}$, and $\mathrm{Nb}$ interlayers, which also indicated that a large amount of plastic deformation occurred in the interlayers during the hot rolling process.

The recrystallization conditions of the cross sections of four clad steel plates after the hot rolling process are presented in Fig. 8, in which yellow represents a substructured structure, blue represents a recrystallized structure, and red represents a deformed structure. The deformed structure in the 2205 stainless steel is prevalent, and it further verifies the results determined in Figs. 6 and 7. The proportions of the substructured, recrystallized, and deformed structures in the entire cross sections of the four clad steel plates were basically similar, as shown in Fig. 9. The recrystallized structure in the 2205 stainless steel had basically the same proportions as the deformed structure [24], and the substructured structure had a very small proportion. This is mainly because the 2205 stainless steel was affected by the large plastic deformation and higher temperature during the hot rolling process. Recrystallized and substructured structures were mainly present in the Q235B low-carbon steel. The deformation of the Q235B low-carbon steel was slight and was only affected by the temperature during the hot rolling process. In addition, the locations of the $\mathrm{Ni}$ and $\mathrm{Nb}$ interlayers were comprised of recrystallized and deformed structures, which further demonstrates that under the condition of hot rolling, the interlayer produced a larger plastic deformation. Recrystallization of the interlayers was carried out under the high temperature conditions.

\subsection{Shear Strength}

The shear strength of the original 2205/Q235B clad steel plate was about $431 \mathrm{MPa}$, as shown in Fig. 10. However, the shear strength decreased with the addition of the three interlayers. The shear strengths of the clad steel plates with the $\mathrm{Fe}$ and $\mathrm{Ni}$ interlayers were reduced by about $14 \mathrm{MPa}$ and $40 \mathrm{MPa}$, respectively, compared with the original clad steel plates. In contrast, the shear strength after the addition of the $\mathrm{Nb}$ layer exhibited a cliff-like decline and decreased by about $282 \mathrm{MPa}$. The good bonding strength of the 2205/ Q235B clad steel plate depends on the plastic deformation and element diffusion in the hot rolling process. The 2205 stainless steel and Q235B low-carbon steel had excellent wetting effects because they mainly contained Fe elements.
Although the interlayers were characterized by plastic deformation and element diffusion phenomena, the addition of the interlayer added a binding interface. The strength of pure Fe is not sufficient, which allowed the interlayer to be easily fractured, even though the Fe interlayer had excellent wetting ability with the 2205 stainless steel and Q235B lowcarbon steel. The Ni interlayer not only had low strength, but also displayed low wetting ability with the two kinds of steel. Therefore, the shear strength was reduced to some extent.

The addition of the $\mathrm{Nb}$ interlayer formed $\mathrm{Nb}-\mathrm{Mo}$ binary intermetallic compounds by consuming Mo elements in the 2205 stainless steel near the bonding surface. This may be the reason for the significant decrease in the shear strength of the clad steel plate with the $\mathrm{Nb}$ interlayer, but further verification is required. Although the shear strengths of clad steel plates with $\mathrm{Fe}$ and $\mathrm{Ni}$ interlayers decreased compared with the original 2205/Q235B clad steel plates, they all exceeded the lowest shear strength specified in the GB/T 8165-2008 standard (210 MPa) [25]. The clad steel plate with the $\mathrm{Nb}$ interlayer had a shear strength lower than the engineering standard, and therefore, it did not meet the requirements of engineering applications.

Figure 11 shows the micromorphologies of shear fractures of the 2205/Q235B duplex stainless steel composite plates with different interlayers. The shear fractures of the clad steel plates with the Fe and Ni interlayers were similar to that of the original clad steel plate. There were many dimples and a large shear lip, indicating that the addition of these two interlayers could effectively guarantee the shear strength of the clad steel plate. After the $\mathrm{Nb}$ interlayer was added, the fracture exhibited an obvious cleavage fracture morphology [26], and there were many large particles in the fracture microstructure. As shown in Fig. 12, EDS was used to detect alloy elements in the large particles and surrounding microstructures presented in Fig. 11d. The large-sized particles ( $\mathrm{A}$ and $\mathrm{B}$ regions) mainly contained $\mathrm{Nb}$ and $\mathrm{C}$ elements, and area $\mathrm{C}$ mainly contained $\mathrm{Fe}$ and $\mathrm{Cr}$ elements. In addition to large amounts of $\mathrm{Fe}$ and $\mathrm{Cr}$ elements, region $\mathrm{D}$ also contained $\mathrm{Nb}$ elements. This indicates that the large particles were $\mathrm{NbC} x$, and the surrounding structure was 2205 stainless steel. $\mathrm{Nb}$ is a strong carbide and nitride-generating element, and it could combine with the $\mathrm{C}$ element in the Q235B low-carbon steel to form stable and brittle $\mathrm{NbC}$ and $\mathrm{Nb}_{6} \mathrm{C}_{5}$ carbides. These carbides easily fracture and crack under the action of shear force [27-29]. The formation of $\mathrm{NbC}$ and $\mathrm{Nb}_{6} \mathrm{C}_{5}$ carbides simultaneously reduced the content of the $\mathrm{C}$ element on the side of the Q235B low-carbon steel near the interlayer, forming a decarburization area, as shown in Fig. 2 d. 


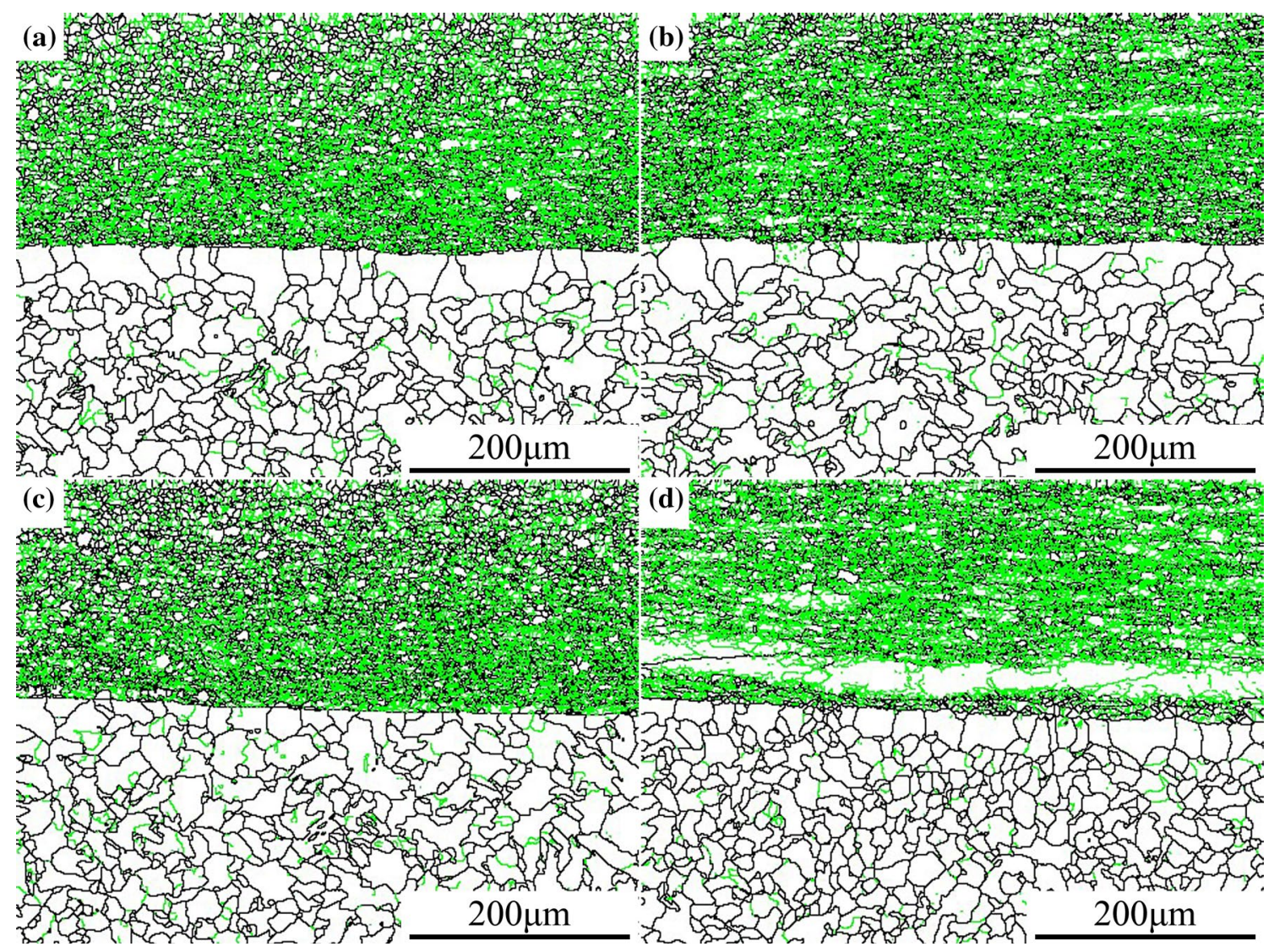

Fig. 7 Distribution rules of the grain boundary of the cross sections of the 2205/Q235B clad steel plates with different interlayers: a without interlayer; b Fe interlayer; $\mathbf{c} \mathrm{Ni}$ interlayer; $\mathbf{d} \mathrm{Nb}$ interlayer

\subsection{Micro-hardness}

At the interface, the micro-hardness of non-intermediate layer and Fe interlayer is very close, as shown in Fig. 13. After adding $\mathrm{Nb}$ interlayer, the hardness of $\mathrm{Nb}$ interlayer is slightly lower than that at the composite interface. After $\mathrm{Ni}$ interlayer is added, the hardness of $\mathrm{Ni}$ interlayer is the lowest. The Q235B side near the composite interface after adding $\mathrm{Ni}$ interlayer had the highest micro-hardness, and the Q235B side near the composite interface after adding $\mathrm{Fe}$ and $\mathrm{Nb}$ had the same micro-hardness, while Q235B side without the interlayer had the lowest micro-hardness, which was related to whether the thick decarburization layer with all-ferrite was formed on the Q235B side, as shown in Fig. 1. After the addition of $\mathrm{Nb}$ interlayer, the micro-hardness of the 2205 side was slightly lower than that of other samples, which was caused by the existence of thick ferrite strip structure. At the distance of $140 \mu \mathrm{m}$ from the composite interface, the micro-hardness stabilized at the hardness level of 2205 parent material.

\subsection{Corrosion Properties of the Cross Sections of Clad Steel Plates}

The macroscopic and microscopic morphologies of the four cross sections of the clad steel plates soaked in acid indicated that the 2205 duplex stainless steel still presented a bright color, while the Q235B low-carbon steel lost its luster, as shown in Fig. 14. These results indicate that the corrosion resistance of the 2205 stainless steel was significantly higher than that of the Q235B low-carbon steel. The regions of the Q235B low-carbon steel near and far away from the bonding surface formed a certain height difference in the corrosion morphology. Without any interlayers, the C element diffused from the Q235B low-carbon steel to the 2205 stainless steel. The area of the low-carbon steel near the bonding surface formed the ferrite. Thus, this area was seriously corroded because the ferrite had a lower potential. The pure iron easily corroded first due to its lower corrosion resistance. The microscopic morphology presented a deep corrosion pit at the position of the $\mathrm{Fe}$ interlayer in the cross section. The side of the Q235B low-carbon steel near the $\mathrm{Nb}$ interlayer also formed a deep corrosion pit because the area of the C element in the Q235B low-carbon steel combined 


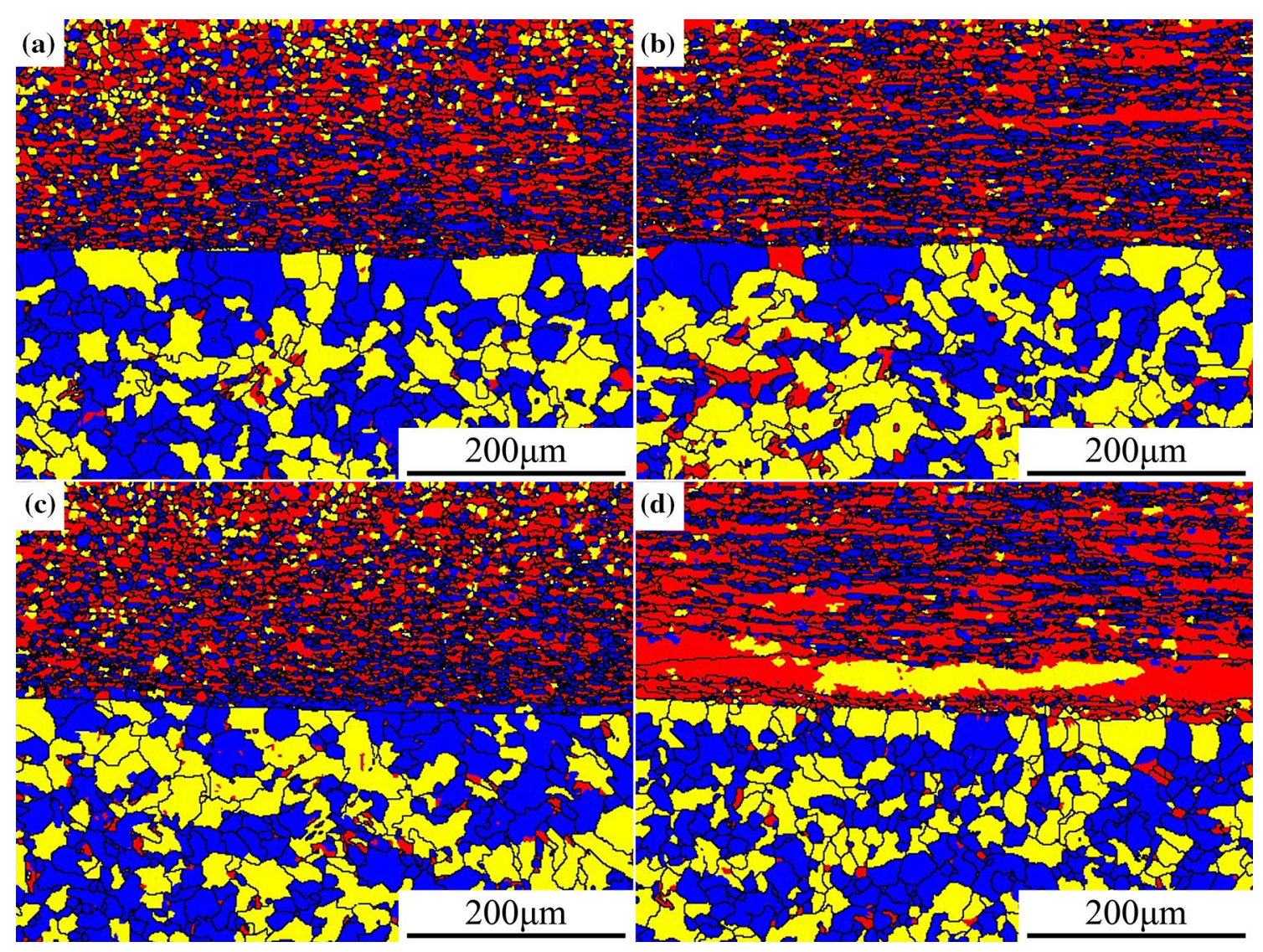

Fig. 8 Distribution rules of the recrystallization of the cross sections in the 2205/Q235B clad steel plates with different interlayers: a without interlayer; b Fe interlayer; c Ni interlayer; $\mathbf{d} \mathrm{Nb}$ interlayer

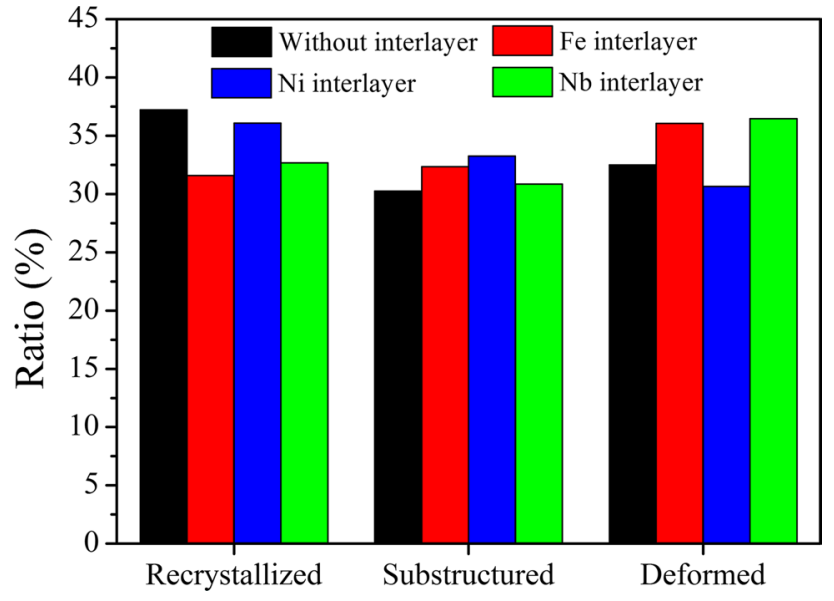

Fig. 9 Recrystallization ratio of the cross sections in the 2205/Q235B clad steel plates with different interlayers

with the $\mathrm{Nb}$ element in the $\mathrm{Nb}$ interlayer to form $\mathrm{NbC} x$. The microstructure of this region will become pure ferrite with a low corrosion resistance, and the brittle $\mathrm{NbC} x$ will easily crack under the action of external force. However, the $\mathrm{Ni}$ interlayer effectively hindered the diffusion of the $\mathrm{C}$ element.

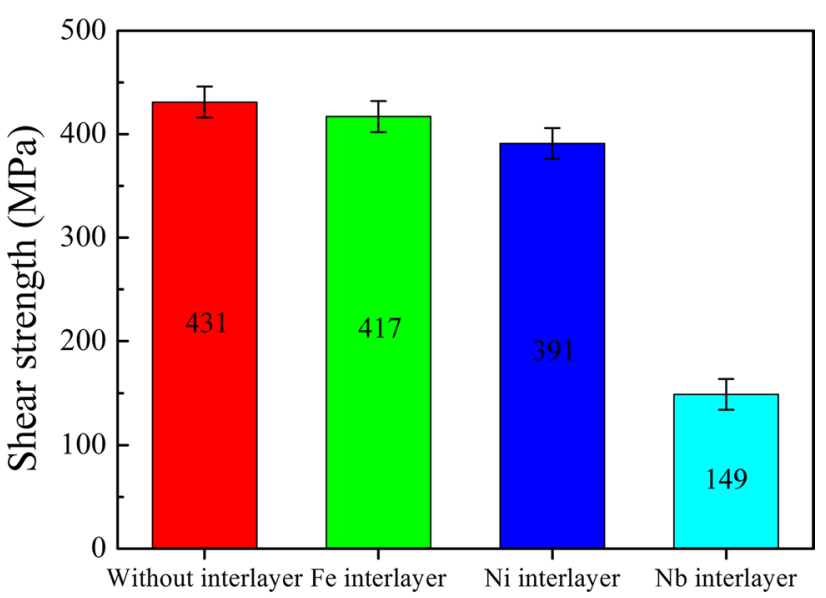

Group

Fig. 10 Shear strengths of the 2205/Q235B clad steel plates with different interlayers

The microstructure of the Q235B low-carbon steel did not change significantly, and the potential basically remained at the same level. Therefore, the corrosion morphology of the Q235B low-carbon steel was basically at one plane. 

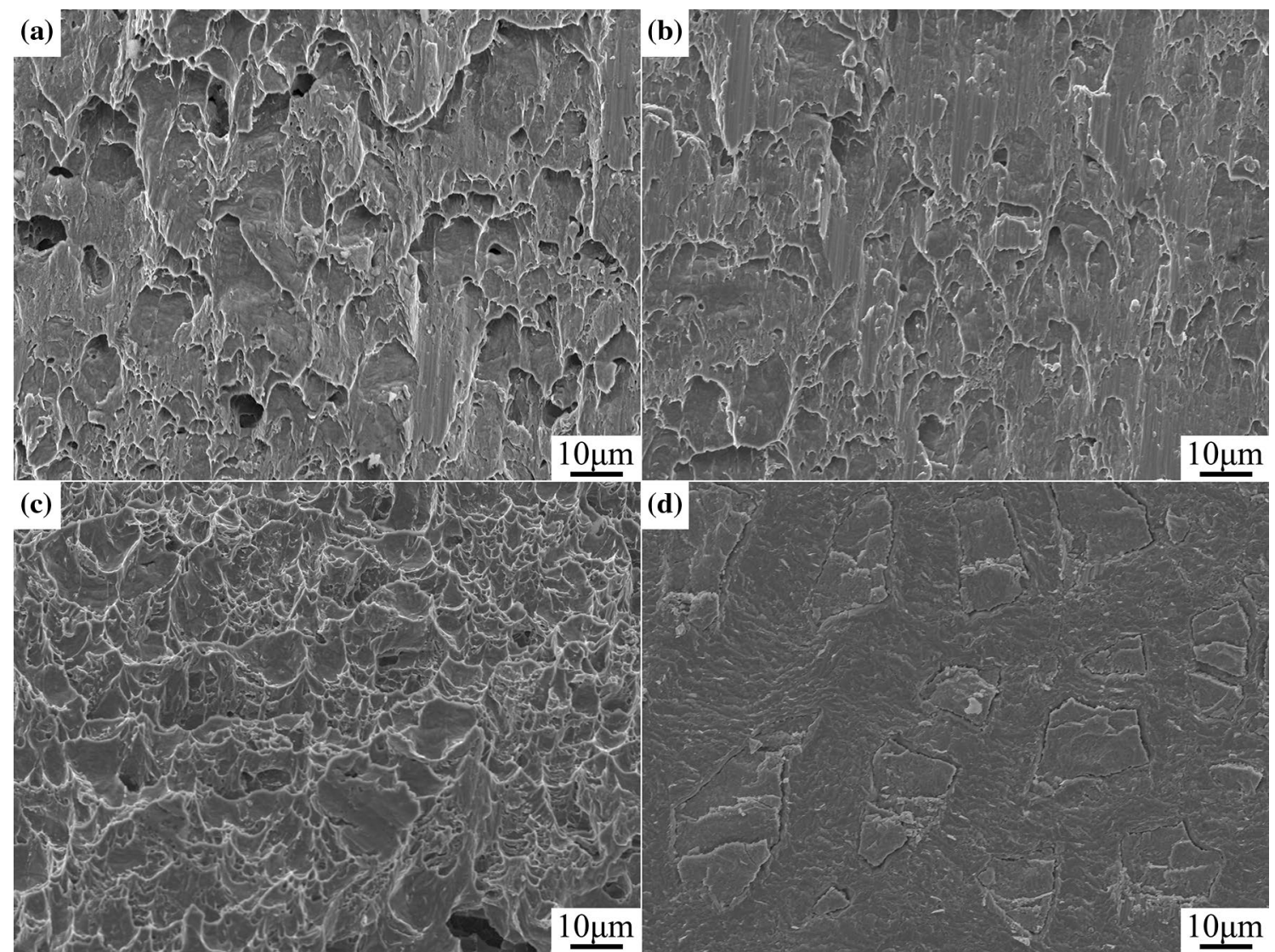

Fig. 11 Micromorphologies of shear fractures of the 2205/Q235B clad steel plates with different interlayers: a without interlayer; b Fe interlayer; c Ni interlayer; $\mathbf{d} \mathrm{Nb}$ interlayer
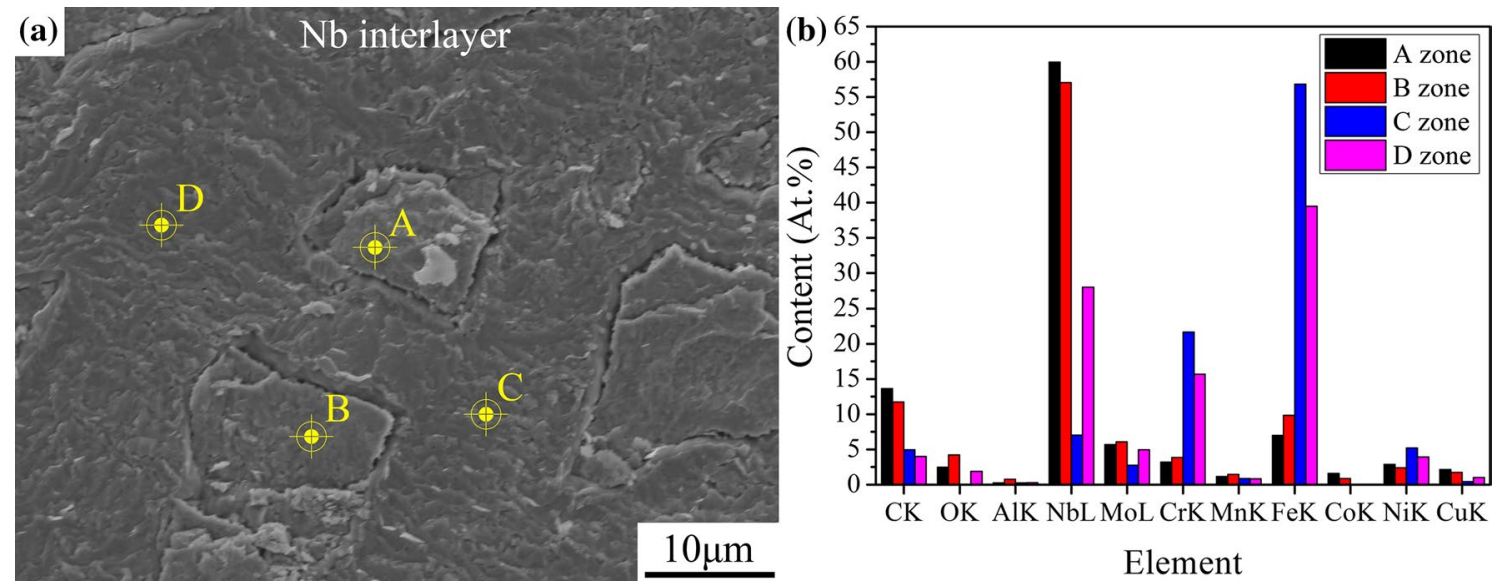

CK OK AlK NbL MoL CrK MnK FeK CoK NiK CuK

Element

Fig. 12 Fracture morphologies and EDS results of shear fractures of the 2205/Q235B clad steel plates with Nb interlayers

In summation, with the addition of the $\mathrm{Nb}$ interlayer, the $\mathrm{Nb}-\mathrm{Mo}$ binary intermetallic compound was formed by combining with the Mo element in the 2205 stainless steel, resulting in the formation of large-sized ferrite strips in the area near the interface. On the other hand, the $\mathrm{Nb}$ element formed a brittle $\mathrm{NbC} x$ with the $\mathrm{C}$ element in the
Q235B low-carbon steel, which significantly reduced the shear strength of the clad steel plate. Moreover, the reduction of the corrosion resistance of the bonding zone occurred because the $\mathrm{C}$ element near the interface on the side of the Q235B low-carbon steel was consumed. Although the addition of the $\mathrm{Fe}$ interlayer had a small impact on the shear 


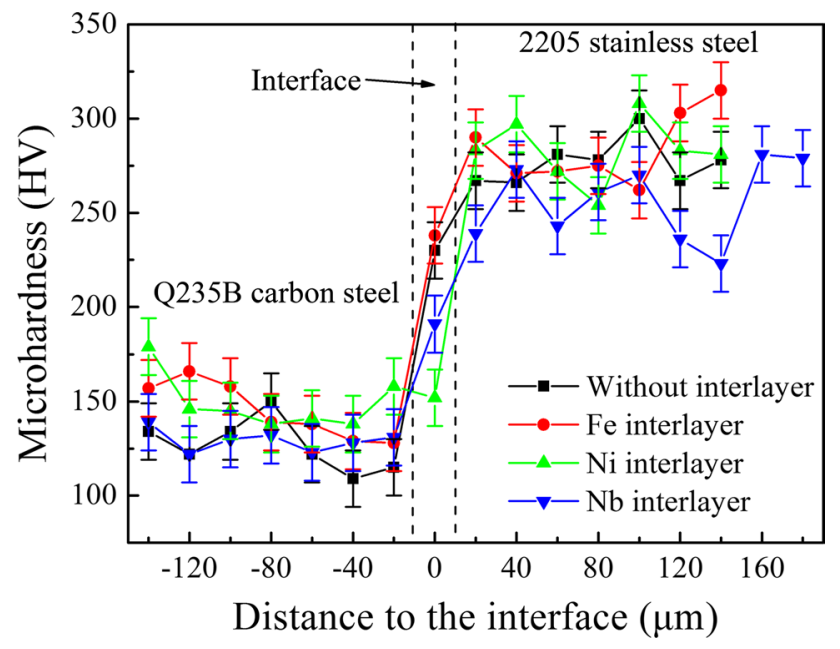

Fig. 13 Micro-hardness distribution curves through the interfaces

strength, it was not conducive to the improvement of the corrosion resistance of the bonding zone due to its low potential. The Ni interlayer also reduced the shear strength of the clad steel plates, but it still met the requirements of engineering standards. The Ni interlayer effectively hindered the element diffusion between the 2205 stainless steel and the Q235B low-carbon steel, thereby endowing the cross section of the clad steel plates with a better corrosion resistance. Therefore, to improve the comprehensive performance of the 2205/Q235B clad steel plate, the Ni interlayer is the best choice among the three intermediate layers.

\section{Conclusions}

(1) When the Ni interlayer was added, there was no obvious decarburization layer on the Q235B low-carbon steel side. In contrast the $\mathrm{Fe}$ and $\mathrm{Nb}$ interlayers made the Q235B side have an obvious decarburization layer, the width of which was smaller than that of the original clad steel plate.

(2) During the rolling process, the 2205 stainless steel and the $\mathrm{Fe}, \mathrm{Ni}$, and $\mathrm{Nb}$ interlayers produced a large number of plastic deformations. The plastic deformation of the Q235B low-carbon steel was small.

(3) The 2205 stainless steel and three interlayers were affected by the large plastic deformation and the high
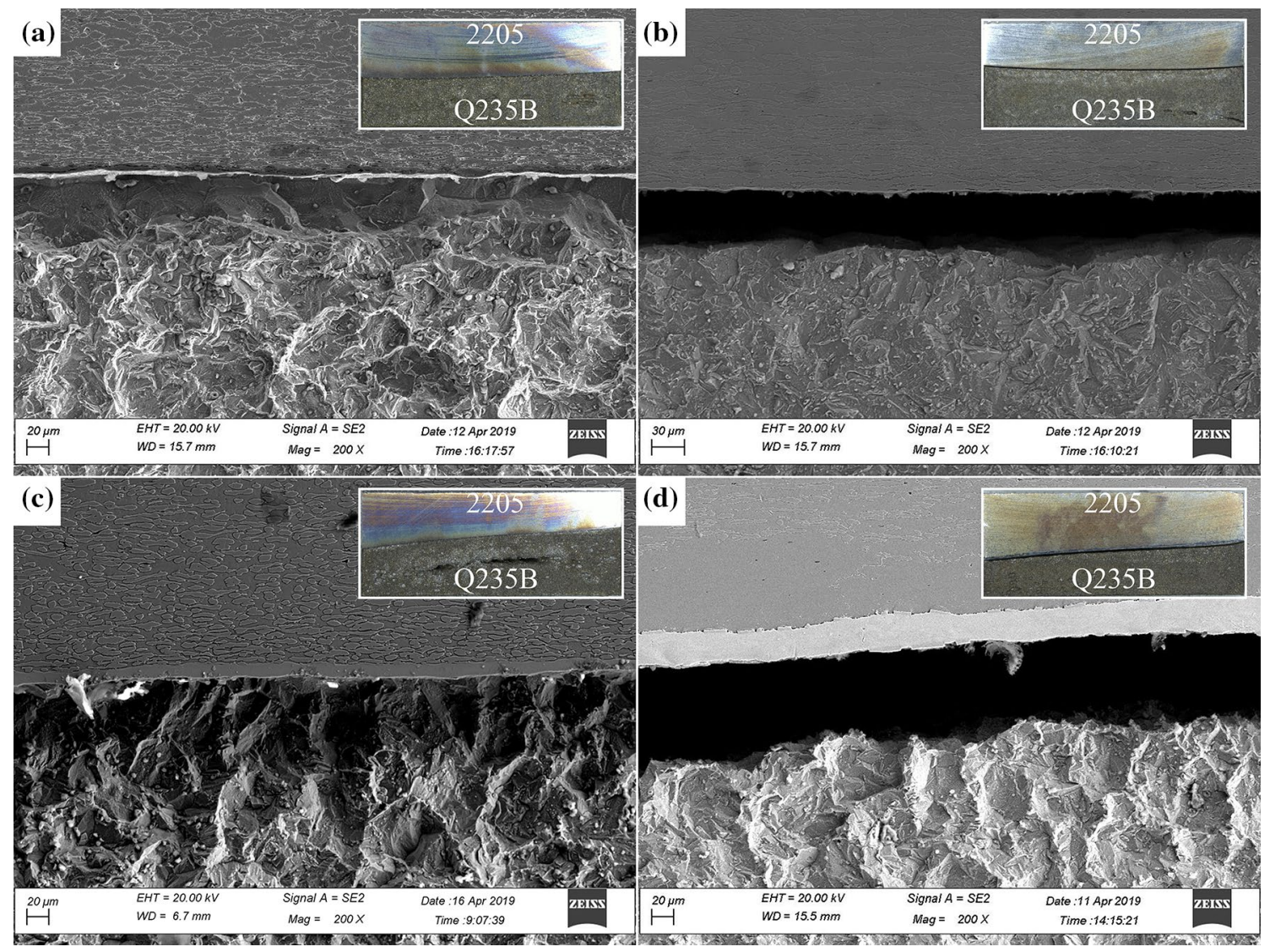

Fig. 14 Microstructures of the acid soaking of the cross sections of the 2205/Q235B clad steel plates with different interlayers: a without interlayer; b Fe interlayer; $\mathbf{c} \mathrm{Ni}$ interlayer; $\mathbf{d} \mathrm{Nb}$ interlayer 
temperature. Their microstructures contained recrystallized and deformed structures. The Q235B low-carbon steel underwent little deformation during hot rolling; it was only affected by the temperature and formed some recrystallization structures.

(4) The shear strength of the original 2205/Q235B clad steel plate was about $431 \mathrm{MPa}$. However, the number of bonding surfaces was increased with the addition of the three interlayers, and the shear strength was decreased to some extent. The shear strengths of the clad steel plates with $\mathrm{Fe}$ and $\mathrm{Ni}$ interlayers still met the requirements of the national standards. However, the hard and brittle $\mathrm{NbC} x$ phase formed in the $\mathrm{Nb}$ interlayer led to a significant decrease of the shear strength.

(5) The addition of the Ni interlayer could effectively prevent the mutual diffusion of elements in the two kinds of steel, so the cross section had an excellent corrosion resistance. The $\mathrm{Fe}$ and $\mathrm{Nb}$ interlayers easily produced the diffusion of elements for the two kinds of steel, which reduced the corrosion resistance of the cross sections.

Acknowledgements This work was financially supported by the Shandong Taishan Industry Leading Talents Project (SF1503302301). And authors thank for the help of Shandong Iron \& Steel Group Co., LTD in the experiment of raw materials.

\section{References}

[1] Y.F. Meng, K. Kang, M. Gao, X.Y. Zeng, Metall. Mater. Trans. A 50(6), 2817 (2019)

[2] Z.M. Wang, S.M. Kang, M.L. Xu, Y.Q. Cheng, M. Dong, Materials 12(9), 1556 (2019)

[3] D.H. Yang, Z.A. Luo, G.M. Xie, T. Jiang, S. Zhao, R.D.K. Misra, Mater. Sci. Eng. A Struct. 753, 49 (2019)

[4] T. Yu, Y.A. Jing, X.L. Yan, W.B. Li, Q.H. Pang, G. Jing, J. Mater. Process. Technol. 266, 264 (2019)
[5] H. Suenaga, M. Ishikawa, K. Minakawa, Japan Patent, JP3035886(A) (1991)

[6] B.X. Li, Z.J. Chen, W.J. He, P.J. Wang, J.S. Lin, Y. Wang, L. Peng, J. Li, Q. Liu, Mater. Sci. Eng. A Struct. 749, 241 (2019)

[7] D.Q. Wang, Z.Y. Shi, R.B. Qi, Scr. Mater. 56, 369 (2007)

[8] F. Takashi, S. Yasunobu, J. Jpn. Soc. Technol. Plast. 512(44), 916 (2003)

[9] Y. Li, Y.M. Zhu, X.F. Zhou, Y.L. Yang, Acta Metall. Sin. 31(12), 537 (1995). (in Chinese)

[10] G.M. Xie, G.L. Wang, Z.A. Luo, China Patent, CN 102178405A (2011)

[11] S. Sam, S. Kundu, S. Chatterjee, Mater. Des. 40, 237 (2012)

[12] D.S. Zhao, J.C. Yan, Y.J. Liu, T. Nonferr, Met. Soc. 24(9), 2839 (2014)

[13] S. Kundu, S. Chatterjee, Mater. Charact. 5(9), 631 (2008)

[14] L. Li, X.J. Zhang, G. Liu, H.Y. Fu, M.N. Li, Trans. Mater. Heat Treat. 36(1), 80 (2015). (in Chinese)

[15] Z.A. Luo, G.L. Wang, G.M. Xie, L.P. Wang, K. Zhao, Chin. J. Nonferr. Met. 23(12), 3335 (2013). (in Chinese)

[16] G.M. Xie, D.H. Yang, Z.A. Luo, Materials 11, 1 (2018)

[17] C. Yu, H. Xiao, H. Yu, Z.C. Qi, C. Xu, Mater. Sci. Eng. A Struct. 695, 120 (2017)

[18] C. Yu, Y.P. Zhao, P.P. Xu, J.K. Ren, H. Xiao, Iron Steel 35(11), 93 (2018). (in Chinese)

[19] B.X. Liu, Q. An, F.X. Yin, S. Wang, C.X. Chen, J. Mater. Sci. 54, 11357 (2019)

[20] B.X. Liu, S. Wang, W. Fang, F.X. Yin, C.X. Chen, Mater. Charact. 148, 17 (2019)

[21] China Standard, GB/T 6396-2008 (2008)

[22] C. Zhang, Y.B. Peng, P. Zhou, W.B. Zhang, Y. Du, Calphad 51, $104(2015)$

[23] J.C. Lippold, D.J. Kotecki, Welding Metallurgy and Weldability of Stainless Steels (Wiley, 2005)

[24] G.W. Fan, J. Liu, P.D. Han, G.J. Qiao, Mater. Sci. Eng. A Struct. 515, 108 (2009)

[25] China Standard, GB/T8165-2008 (2008)

[26] Z.A. Luo, G.L. Wang, G.M. Xie, L.P. Wang, K. Zhao, Acta Metall. Sin. (Engl. Lett.) 26(6), 745 (2013)

[27] H.T. Yan, H.Y. Bi, X. Li, Z. Xu, Iron Steel 44(1), 59 (2009). (in Chinese)

[28] Z.X. Wang, T.Z. Wang, Y.X. Xie, Z.Y. He, B. Tang, Nucl. Technol. 34(1), 36 (2011). (in Chinese)

[29] S.M. Abbasi, A. Shokuhfar, J. Iron Steel Res. Int. 14(6), 74 (2007) 